\title{
Suspects' Consistency in Statements Concerning Two Events when Different Question Formats are Used
}

\author{
Haneen Deeb ${ }^{1}$, Aldert Vrij ${ }^{1}$, Lorraine Hope ${ }^{1}$, Samantha Mann ${ }^{1}$, Pär-Anders Granhag ${ }^{2}$, \\ Gary Lancaster ${ }^{1}$ \\ ${ }^{1}$ University of Portsmouth, Department of Psychology, United Kingdom \\ ${ }^{2}$ University of Gothenburg, Department of Psychology, Sweden
}

Author Note

This research was supported by the Erasmus Mundus Joint Doctorate in Legal Psychology Programme, Award 2014 - 0678.

We would like to thank Veronica Fardella, Emily Ingram, and Nicola Palena for their assistance with data collection.

Correspondence concerning this manuscript should be addressed to Haneen Deeb, Department of Psychology, University of Portsmouth, King Henry I Street, PO1 2DY, Portsmouth, United Kingdom. Telephone: 0044 (0) 239284 6312. Fax: 0044 (0) 2392846300. Email: haneen.deeb@port.ac.uk. 


\begin{abstract}
Lie detection research has typically focused on reports about a single event. However, in many forensic and security contexts, suspects are likely to report on several events, some of them may be untruthful. This presents interviewers with the challenge of detecting which reports are true and which are not. Varying question format in a second interview, we examined differences in liars' and truth-tellers' statement inconsistency about two events. One hundred and fifty participants viewed a meeting in which a non-critical and a critical event were discussed. Truthtellers were instructed to be honest in their reports about both events, whereas liars had to lie about the critical event. In the first interview, all participants provided a free recall account. In a second interview, participants either gave another free recall account or responded to specific questions presented sequentially (concerning one event at a time) or non-sequentially (concerning both events simultaneously). Liars' accounts featured more repetitions than truthtellers for both events, particularly in response to questions presented in non-sequential order. The implications for the use of this question format are discussed.
\end{abstract}




\section{Suspects' Consistency in Statements Concerning Two Events when Different Question Formats are Used}

Lie detection research has typically focused on reports about a single event. However, in many forensic and security contexts, investigators may interrogate suspects about more than one event. This may be especially the case with police informants who often offer multiple pieces of information, some of which may be unreliable (Harfield, 2012; Stabile, 2014). Informants may provide inaccurate information to receive rewards (e.g. money, legal status or permanent residence permit), seek revenge from a competitor, or escape incarceration (Harfield, 2012; McGarrell, Freilich, \& Chermak, 2007; Miller, 2011). In terrorist cases, informants may lie to investigators about the details of a planned terrorist attack or about a terrorist's identity (Greer, 1995; Stabile, 2014). Despite informants not always providing truthful information, investigators continue to use informants in criminal and terrorist cases as they are considered vital and costeffective sources of information in unresolved cases (Innes, 2000; Maguire \& John, 1995; Stabile, 2014). Hence, it is important to explore interrogation techniques that may assist law enforcement agencies to effectively distinguish between truthful and deceptive informants when an interview involves questioning about more than one event.

Inconsistency is frequently cited by investigators as the most useful cue for detecting lies in suspect statements (Strömwall \& Granhag, 2003). In repeated statements, information is typically considered inconsistent if subsequent statements include few repetitions, omissions (details provided in an earlier statement but not in a subsequent statement), reminiscences (details provided in a subsequent statement but not in an earlier statement), and/or contradictions (conflicting details across statements; Fisher, Brewer, \& Mitchell, 2009; Granhag, Strömwall \& Jonsson, 2003; Vredeveldt, van Koppen, \& Granhag, 2014). 
In an examination of truth-tellers' and liars' inconsistency across multiple interviews, Granhag, Strömwall, and colleagues found that when statements regarding a single event were repeated over time, liars were equally or less inconsistent than truth-tellers (e.g., Granhag \& Strömwall, 2002; Granhag et al., 2003). These findings negate the consistency heuristic which assumes that liars provide inconsistent statements whereas truth-tellers provide consistent statements (Strömwall \& Granhag, 2003). Granhag and colleagues interpreted these findings in light of a 'repeat versus reconstruct' hypothesis. This hypothesis postulates that liars prepare and rehearse their responses before the first interview. When they are interviewed again, liars attempt to repeat those responses to maintain their statement consistency which they assume gives an impression of honesty. In contrast, truth-tellers do not rely on rehearsing and repeating their responses but instead rely on their memory of the event. Therefore, truthful statements across interviews are more likely to appear inconsistent because, as a function of natural remembering, some information in a repeated interview may be different. For example, truth-tellers may add extra information (reminiscences) or forget some information (i.e. omissions; Fisher et al., 2009).

The rehearsal strategy used by liars may be counteracted by asking questions in a different format across interviews (Leins, Fisher, \& Vrij, 2012). Liars should find it more difficult to respond to a changed question format, because they have not experienced or encoded the relevant event, so more inconsistencies are likely to emerge in their statements. To test this hypothesis, Leins et al. (2012) asked interviewees to respond in different modes, (either verbally or pictorially) across two interviews. Liars were more inconsistent (provided significantly fewer repetitions and more contradictions) than truth-tellers when they reported their statements in different modes but not when they reported their statements verbally or pictorially only; no significant differences were found for reminiscences and omissions. Leins and colleagues also 
explored the strategies participants used to appear credible during the interview. Eighty eight percent of the liars reported that they used consistency during the second interview, whereas only $42 \%$ of the truth-tellers reported using this strategy. Hence, even though liars attempted to maintain consistency, they failed to achieve that when the interview format was changed.

In another study, interviewees were asked to report an event in chronological order and then again in reverse order to the same or to a different interviewer (Shaw et al., 2014). Liars provided significantly fewer repetitions than truth-tellers but only when the interviewer was changed in the second interview. When this reverse order technique was used with non-native speakers in the presence of an interpreter, liars repeated the same number of details but reminisced significantly fewer details than truth-tellers (Ewens, Vrij, Mann, \& Leal, 2015).

These studies demonstrate that asking questions in a different format across repeated interviews about a single event increases inconsistencies in liar' statements but not in truthtellers' statements. In the present study, we devised a strategic questioning approach to assess inconsistencies across statements when a suspect is interviewed about two or more events. Specifically, suspects were asked in the first interview to provide separate free recall accounts on witnessed discussions about a non-critical event and about a critical event. Truth-tellers were instructed to report both events truthfully, whereas liars were asked to tell the truth about the non-critical event and to lie about the critical event. This procedure simulated real life scenarios in which deceptive informants report a mixture of true and false information so that their responses are believed by investigators (Maguire \& John, 1995; Stabile, 2014). Informants typically strive to appear credible, so they may volunteer trivial information the investigator already knows (Rosenfeld, Jacobs, \& Wright, 2003). To simulate this situation, we required liars in the current study to tell the truth about one of the events (the non-critical event that concerned 
less important information than the critical event and about which the interviewer was already informed).

In the second interview, participants were required to produce further free recall accounts for both events or were asked a series of specific questions for details of the events. Questions were asked either (i) separately about each event with the order of questioning following the order of the witnessed events (sequentially ordered questions), or (ii) simultaneously about both events with the order of questioning not following the order of the witnessed event (nonsequentially ordered questions). In line with previous findings regarding change in question format, these specific questions were expected to increase statement inconsistency for liars more than for truth-tellers. The free recall account would be easy for liars as they already provided the account in the first interview. Also, free recall accounts allow liars to be vague and evasive (Granhag \& Strömwall, 1999; Hartwig et al., 2011). Specific questions, on the other hand, require suspects to provide specific responses (Evans \& Fisher, 2011) which liars find more difficult than truth-tellers, particularly if liars have not experienced the event on which they are reporting. More precisely, the non-sequentially ordered questions were expected to disrupt reliance on sequentially rehearsed responses and to exhaust the cognitive resources of liars which further increase the differences between liars' and truth-tellers' statement inconsistency.

We predicted that when liars tell the truth (i.e., discussing the non-critical event twice), they would be as consistent as truth-tellers in their statements. The predicted consistency in truth-tellers' statements is based on the eyewitness recall literature. Truthful witnesses tend to be more consistent when they are asked the same questions across interviews than when they are asked different questions (for an overview, see Fisher et al., 2009). Hence, we expected that all participants recalling the non-critical event to be more inconsistent when they were asked 
specific questions than when they were asked to repeat a free recall. The non-sequentially ordered questions reflect a more drastic change in the interview format, so we expected participants in the non-sequentially ordered questions condition to be the most inconsistent and those in the free recall condition to be the least inconsistent when reporting about the non-critical event (Hypothesis 1).

As for the critical event about which liars provided false information, we predicted that liars and truth-tellers would not differ significantly with respect to statement inconsistency when they are asked the questions in the same format in both interviews (i.e. free recall), especially that all participants had the chance to prepare their statements prior to the interviews. When questions are asked in a different format, liars can no longer use the rehearsed responses or repeat responses they provided in a previous interview (for a review, see Fisher, Vrij, \& Leins, 2013). Hence, we expected liars to become significantly more inconsistent than truth-tellers when reporting about the critical event if the question format is changed between the interviews, particularly when the question format in the second interview is dramatically different to that in the first interview (i.e. in the non-sequentially ordered questions condition; Hypothesis 2).

We examined within-subjects differences among liars and truth-tellers. We expected truth-tellers' performance on inconsistency to be the same for the critical and non-critical events. As lying is more cognitively demanding than truth-telling (Vrij, 2008), we expected liars to be more inconsistent when they lied about the critical event than when they told the truth about the non-critical event (Hypothesis 3).

We were also interested in examining the strategies that suspects use when reporting about two events to convince the interviewer that their statement is credible. When interviewed multiple times, liars typically attempt to maintain consistency to appear credible (Leins et al., 
2012). Hence, we predicted that liars would be more likely than truth-tellers to report using consistency across interviews for both events as a strategy to convince the interviewer of their responses (Hypothesis 4).

\section{Method}

\section{Participants and Design}

A total of 150 participants (68 males, 82 females, $M_{\text {age }}=25.3$ years, $\left.S D_{\text {age }}=8.86\right)$ were recruited through the departmental participant pool and announcements posted in the university buildings, via email and on the university intranet. Participants received a reward of either a participation credit or $£ 5$ for taking part in the research.

A 2 (Veracity [truth-teller, liar]) $\times 3$ (Second Interview Question Format [free recall, sequentially ordered, non-sequentially ordered]) between-subjects design was used. The dependent variables were the Number of Repetitions, Reminiscences, and Contradictions reported across both interviews for both critical and non-critical events. The Number of Omissions may be deduced from repetitions as fewer repetitions means more omissions. Participants were randomly assigned to the Veracity conditions (75 participants in each condition) and to the Second Interview Question Format conditions (50 participants in each condition).

\section{Materials}

A video of a 4-min Skype meeting was produced for the purpose of the study. The meeting was between three undercover agents named 'Chief', 'Tiger', and 'Bird'. Each of them was given certain character features that were evident in their discussion: Chief made the decisions, Bird complained about those decisions, and Tiger was the enthusiastic agent who 
often criticized Bird. The agents had two discussions about two separate events. The Skype meeting started with the agents discussing a non-critical event about a field trip to Prague to meet and collaborate with Czech agents. Then, they discussed a critical event about a potential terrorist attack in London. This discussion involved an exchange about how to plant a spying device in the workplace of the suspected terrorist under the guise of presenting a workshop.

\section{Procedure}

After participants signed the informed consent form, they were instructed to imagine that they worked as undercover agents for an Intelligence Agency and that they were authorized to view a confidential Skype meeting between three undercover agents who work for the Agency. They had to pay attention to everything in the meeting as they were to be interviewed about the meeting afterwards. The experimenter waited outside the room while the participants viewed the meeting video. Participants were then randomly assigned to either the truth-teller or liar condition. Truth-tellers read on the computer screen that there was a spy working in the Agency, and this alleged spy aimed to protect the terrorist and stop the three agents from tracking him. As the Agency suspected that the spy was able to trace the online meeting, the participant was to be interviewed to know what information might have leaked. Therefore, participants needed to report everything that happened as honestly as possible so that the interviewer would not conclude they were hiding relevant information.

Liars read similar instructions, but they were informed that they would be interviewed by the alleged spy. The Agency wanted to check if the alleged spy would act on any information the participant might reveal. If the alleged spy acted on that information, it would be clear that this person works for the terrorist. Hence, participants had to convince the alleged spy they were telling the truth in the following manner: They were to give an honest impression by telling the 
truth about the first (non-critical) event about Prague which the spy knew about and which was not considered to include significant information. The second (critical) event, however, included very sensitive information, so they had to lie about it. As the alleged spy might possess information that the agents were trying to track the suspected terrorist, participants were asked to discuss the spying device but not to reveal the true details regarding how and where it will be planted. Therefore, they needed to fabricate another story in which the spying device would be planted elsewhere. We instructed liars which event to lie about so that all liars' stories would be similar (as would be the case for all truth tellers' stories). Moreover, these instructions helped liars to fabricate a 'believable lie'.

After participants read the instructions, the experimenter verbally clarified the instructions, and reiterated that, to receive the reward, participants needed to convince the interviewer they are being honest. This instruction has been used in many lie detection studies to simulate motivation in real suspect interviews by prompting interviewees, especially liars, to try to convince the interviewer that they are being truthful (e.g. Vrij et al., 2009). Participants were given as much time as they needed to prepare for the interview.

One of four interviewers, blind to the participants' veracity condition, and to the study hypotheses interviewed the participants. In the first interview, all participants were asked to give a detailed free recall about what each of the agents said about the non-critical event followed by another request to give a free recall about what each agent said about the critical event. This request for a free recall account simulates the information gathering approach used by investigators (Vrij, Granhag, \& Porter, 2010). At the end of this interview, participants were asked to think back and to try and remember any details they might have missed. After participants provided their statements, the interviewer gave them a crossword puzzle to complete 
and apologized for having to leave the room. Participants worked on this filler task for 10 minutes.

Afterwards, the same interviewer conducted the second interview in which participants were randomly assigned to the free recall condition, sequentially ordered questions condition, or non-sequentially ordered questions condition. Those in the free recall condition were again asked to freely recall as much as they could about each discussed event. Participants in the sequentially ordered questions condition were asked questions about what each of the agents said in the noncritical event followed by the same questions about the critical event. Participants in the nonsequentially ordered questions condition responded to questions alternating between the critical and non-critical events (See Appendix for the questions asked). At the end of this interview, all participants were prompted to think back and to try and remember any details they might have missed.

Participants then completed a post-interview questionnaire that assessed their motivation to convince the interviewer of their responses on a 7-point Likert scale $(1=$ not motivated at all to $7=$ very motivated $)$. They also responded to an open-ended question on the strategy they used to make their responses credible across interviews. Participants were then fully debriefed and thanked.

\section{Coding}

All interviews were transcribed and then coded by one rater. Every noun, verb, adjective, or adverb that interviewees used to describe what an agent said was marked as a single detail. These details were categorized for each agent such that each detail referred to one of the agents. For example, the statement 'the Chief was telling them that the terrorist's brother works on a 
train' contains five details (Chief, terrorist, brother, works, train) that are ascribed to the agent Chief. All details mentioned more than once, including the agents' names, were coded only once in any single interview. When it was not clear to which agent the details referred to, the details were coded as 'unspecified' details. Details repeated in the second interview were coded as Repetitions, details that were mentioned in the first interview but not in the second interview were coded as Omissions, details that were mentioned in the second interview but not in the first interview were coded as Reminiscences, and details in the second interview that contradicted relevant details in the first interview were coded as Contradictions.

A second rater blind to the experimental conditions and to the study hypotheses coded the responses of 24 participants ( $20 \%$ of the total sample). The rater started by coding interviews with four participants, and disagreements with the first rater were discussed and resolved. Then, the rater coded the responses of the remaining 20 participants. An inter-rater reliability analysis revealed that the Intra-class Correlations (ICC) were .97 for Repetitions, .92 for Omissions, .85 for Reminiscences, and .57 for Contradictions.

We were interested in liars' strategies when they report truthful and false information about separate events. Hence, two raters coded participants' responses to the post-interview question on the strategy they used to appear credible during the interview. Strategies were coded into general categories which were data driven (i.e. not predetermined).

Truth tellers' responses were categorized into five categories, and liars' responses were categorized into six categories. The categories that emerged for truth tellers were: (a) providing details (e.g., 'I tried to include as much information as possible'), (b) being honest (e.g., 'I just told the truth about what I have seen'), (c) reporting in chronological order (e.g., 'I tried to remember everything in sequence'), (d) using memory enhancement strategies (e.g 'I put myself 
in the agent's position to be able to connect the information'), and (e) maintaining consistency (e.g., 'I tried to be consisted in the information I delivered').

For liars, the categories that emerged were: (a) maintaining consistency (e.g., 'I hesitated when asked about the trip to Prague so that if I hesitated when asked about the spy mission, it might not sound so obviously different to the usual way in which I answered questions'), (b) appearing truthful (e.g., 'I tried to keep some details that were in the actual discussion'), (c) providing details (e.g., 'I gave as many details and reasons as possible for the agents' actions'), (d) keeping the story simple (e.g., 'Don't over explain things; try to keep it easy to remember'), and (e) rehearsing (e.g., 'I practiced what I thought the conversation would be before going into the interview'). The sixth category labeled 'Other' included strategies that did not fit into the other five categories and that were reported by fewer than four participants (e.g., 'Look him to the eye'). A second rater allocated the responses to these categories. Inter-rater reliability was high $(I C C=.84)$. Disagreements between the raters were discussed and resolved.

\section{Results}

A manipulation check revealed that participants were highly motivated to convince the interviewer that they were telling the truth $(M=5.56, S D=1.23$, on a 7-point Likert scale). A two-way analysis of variance (ANOVA) with Veracity and Second Interview Question Format as the independent variables and rated motivation as the dependent variable did not reveal significant differences between truth-tellers $(M=5.72, S D=1.11)$ and liars $(M=5.40, S D=$ 1.34), $F(1,144)=2.54, p=.113, d=0.26,95 \%$ CI $[0.07,0.46]$. Similarly, motivation was not significantly different between participants in the Free Recall condition $(M=5.34, S D=1.22)$, in 
the Sequentially Ordered Questions condition $(M=5.72, S D=1.23)$, and in the Non-sequentially Ordered Questions condition $(M=5.62, S D=1.24), F(2,144)=1.28, p=.28$, Cohen's $f=.14$.

\section{Hypotheses Testing}

Contradictions and reminiscences ${ }^{1}$ did not occur frequently enough to be analysed, as shown in Table 1. Hence, we could not analyse Contradictions and Reminiscences, so the relevant hypotheses could not be tested and we only report the results for Repetitions.

Table 1 about here

The Number of Details provided at Interview 1 may have affected the Number of Repetitions at Interview 2. That is, the more Details provided at Interview 1, the more opportunities for Repetitions to occur. Hence, we calculated the repetitions proportion scores (Number of Repetitions for the critical or the non-critical event at Interview 2/Number of Details for the critical or the non-critical event at Interview 1) to take into account the Number of Details at Interview 1. The average Number of Details provided at Interview 1 regarding the non-critical event was $33.75(S D=10.80)$ for truth-tellers and $27.95(S D=9.84)$ for liars. As for the critical event, truth-tellers provided an average of 43.65 Details ( $S D=12.46$ ), whereas liars provided an

\footnotetext{
${ }^{1}$ Reminiscences comprised only $11 \%$ of the total number of details for the critical and noncritical events. When we ran an ANOVA with Veracity and Second Interview Question Format as the independent variables and Reminiscences for each of the critical and non-critical events as the dependent variable, we found significant main effects for Veracity and Second Interview Question Format on Reminiscences regarding the non-critical event but not regarding the critical event. We believe that these results are due to the small number of reminiscences. The Veracity main effect regarding the non-critical event revealed that participants in the truth-telling condition provided more Reminiscences than those in the lying condition, $F(1,144)=5.74, p=$ .018. As for Question Format regarding the non-critical event, the Non-sequentially Ordered Questions produced significantly more Reminiscences than the Sequentially Ordered Questions and the Free Recall, $F(2,144)=5.15, p=.007$.
} 
average of 37.48 Details $(S D=14.11)$ at Interview 1. Analyses using the Repetitions proportion scores yielded similar results as the analyses using raw frequencies. We report the data for the raw frequencies because they are more informative. Also, the proportion scores can be inferred from these scores. The analyses for the critical and the non-critical events are presented separately, because liars only lied about the critical event (they told the truth about the noncritical event).

Table 2 about here

Non-critical event. We conducted a 2 (Veracity) $\times 3$ (Second Interview Question Format) ANOVA on the non-critical event data with the Number of Repetitions between the first Free Recall interview and the second interview as the dependent variable. Veracity, $F(1,144)=$ 15.25, $p<.001$, Cohen's $f=.31$, and Second Interview Question Format, $F(2,144)=5.80, p=$ .004 , Cohen's $f=.27$, showed a significant main effect, but no interaction effect emerged, $F(2$, $144)=0.06, p=.942$, Cohen's $f=.03$. As Table 2 shows, liars unexpectedly provided fewer Repetitions than truth-tellers, $d=0.62,95 \%$ CI $[0.29,0.95]$.

Planned comparisons revealed that the Non-sequentially Ordered Questions $(M=21.22$, $S D=8.22)$ elicited significantly fewer Repetitions than the Free Recall $(M=27.50, S D=11.93)$, $t(98)=3.07, p=.003, d=0.61,95 \%$ CI $[0.21,1.01]$. The Sequentially Ordered Questions $(M=$ 22.92, $S D=9.27$ ) did not elicit a significantly different Number of Repetitions than the Nonsequentially Ordered Questions, $t(98)=0.97, p=.334, d=0.19,95 \%$ CI [-0.20, 0.59], or the Free Recall, $t(98)=2.14, p=.053, d=0.43,95 \%$ CI $[0.03,0.83]$. These findings on the Second Interview Question Format are in line with Hypothesis 1, which predicted that statement 
inconsistency will be highest in the Non-sequentially Ordered Questions condition and lowest in the Free Recall condition.

Figure 1 about here

Critical event. A 2 (Veracity) $\times 3$ (Second Interview Question Format) ANOVA on the critical event data, with the Number of Repetitions as the dependent variable, revealed a significant main effect for Veracity, $F(1,144)=32.85, p<.001$, Cohen's $f=.46$, and for Second Interview Question Format, $F(2,144)=5.50, p=.005$, Cohen's $f=.25$. As Table 2 shows, truthtellers provided significantly more Repetitions than liars, $d=0.91,95 \%$ CI $[0.57,1.25]$.

Regarding the Second Interview Question Format main effect, planned comparisons revealed that Non-sequentially Ordered Questions $(M=24.72, S D=10.32)$ elicited significantly fewer Repetitions than the Free Recall $(M=31.14, S D=13.15), t(98)=2.72, p=.008, d=0.54$, $95 \%$ CI $[0.14,0.94]$. The Sequentially Ordered Questions $(M=26.54, S D=9.13)$ did not elicit a significantly different Number of Repetitions than the Non-sequentially Ordered Questions, $t(98)$ $=0.93, p=.352, d=0.19,95 \% \mathrm{CI}[-0.21,0.58]$, or the Free Recall, $t(98)=2.03, p=.068, d=$ $0.41,95 \%$ CI [0.01, 0.80].

No interaction effect emerged between Veracity and Second Interview Question Format, $F(2,144)=0.90, p=.409$, Cohen's $f=.10$. However, this interaction effect was not an appropriate test for Hypothesis 2, because the interaction statistic $(p=.409)$ may refer to any type of interaction. As we predicted a directional effect with specific group differences based on evidence from previous studies, a more informative test of Hypothesis 2 is to statistically test for significant differences between truth tellers and liars in each of the three experimental conditions and to compare the groups' effect sizes to understand the magnitude of differences in each of the three different truth-lie comparisons (for a review on the importance of effect sizes compared to 
significant effects, see du Prel, Hommel, Röhrig, \& Blettner, 2009; Fritz, Morris \& Richler, 2012). The larger the magnitude, the easier it is for investigators to spot the differences between liars and truth-tellers. Hence, for the purpose of our study, the magnitude of the effects play a more important role than the significance of the effects.

Univariate analyses that compared liars and truth-tellers in each Question Format condition were conducted. The results are presented in Table 2. The truth-lie differences were significant in all three comparisons, particularly in the Non-sequentially Ordered Questions condition, $d=1.48,95 \%$ CI $[0.86,2.11], P S=85$. The effect size for Cohen's $d$ may be small (.20), medium (.50), or large (.80; Cohen, 1992). The effect size for this condition was very large, so the differences between liars and truth-tellers could be more easily detected in this condition compared to the Sequentially Ordered Questions condition, $d=0.85,95 \%$ CI $[0.27$, 1.42], $P S=75$, and to the Free Recall condition, $d=0.68,95 \%$ CI $[0.11,1.25], P S=68$. The Sequentially Ordered Questions condition and the Free Recall condition also showed a large effect, but not as large as the Non-Sequentially Ordered Questions condition. Moreover, the lower confidence interval limit of the effect size of Non-Sequentially Ordered Questions condition was far from zero and considerably higher than the two other Question Format conditions, which further corroborates our findings. Also in line with this finding, the probability of superiority $(P S)$ or "the percentage of occasions when a randomly sampled member of the distribution with the higher mean will have a higher score than a randomly sampled member of the other distribution" (Fritz et al., 2012, p. 8) was larger for the Non-Sequentially Ordered Questions condition compared to the two other Question Format conditions. Figure 2 further shows that liars' scores in the Non-Sequentially Ordered Questions condition were lower than liars' scores in the other conditions and also substantially lower than truth-tellers' scores in the 
Non-Sequentially Ordered Questions condition. These results supported Hypothesis 2, which posited that differences in statement inconsistency between liars and truth-tellers would be most pronounced in the Non-sequentially Ordered Questions condition and least pronounced in the Free Recall condition.

Figure 2 about here

We conducted a follow-up discriminant analysis with the Veracity groups as the classifying variable and Repetitions for the critical event as the independent variable to understand how accurately Non-sequentially Ordered Questions could classify liars and truthtellers based on Repetitions. The analysis revealed that $84 \%$ of liars and $72 \%$ of truth-tellers could be classified correctly by the Non-sequentially Ordered Questions, $\chi 2(1)=21.49$, Wilk's Lambda $=0.64, p<.001$, which is more than could be classified correctly by the Sequentially Ordered Questions (72\% of liars and 68\% of truth-tellers) and the Free Recall (68\% of liars and $48 \%$ of truth-tellers).

\section{Comparing repetitions for the critical and non-critical events among liars and truth-}

tellers. We ran separate within-subjects ANOVAs for liars and truth-tellers with Event (noncritical, critical) as the independent variable and Repetitions as the dependent variable to compare Repetitions for the non-critical and critical events within each Veracity group. Truthtellers provided more Repetitions when they reported about the critical event than when they reported about the non-critical event, $F(1,74)=26.42, p<.001, d=0.51,95 \%$ CI $[0.18,0.83]$. Liars' Repetitions for the critical and the non-critical events were not significantly different, $F(1$, $74)=3.51, p=.065, d=0.20,95 \%$ CI $[-0.12,0.52]$. Thus, Hypothesis 3 , which postulated that liars would be more inconsistent when they report about the critical event than when they report about the non-critical event, was not supported. 
Table 3 about here

Reported Strategies. Table 2 shows the frequency of occurrence of each strategy used by liars and truth-tellers. More than half of the truth-tellers attempted to provide as many details as they could to convince the interviewer they were innocent. We were particularly interested in the 'consistency strategy'. This strategy was reported by only $8 \%$ of the truth tellers. Amongst liars, this was the most frequently reported strategy with $45 \%$ of liars reporting having used that strategy. This indicates that half of the liars responded according to the consistency heuristic and attempted to remain consistent across interviews for each event as well as across events so that the interviewer believes they are truthful. The consistency strategy was used significantly more by liars than by than truth-tellers, $\chi 2(7)=138.99, p<.001$, Cramer's $\mathrm{V}=.778$, which supported Hypothesis 4.

\section{Discussion}

The present study examined whether asking questions in a non-sequential order about two events would elicit cues to deceit in terms of statement consistency. All participants told the truth about a non-critical event, but liars had to fabricate new details about a critical event. Across interviews, truth-tellers repeated more details than liars for the critical event. We predicted that for the critical event the differences in repetitions between liars and truth-tellers would be most pronounced in the non-sequentially ordered questions condition and least pronounced in the free recall condition. Hence, we were interested in the magnitude of the difference between truth-tellers' and liars' repetitions in each of the question format conditions. Our results revealed that truth-tellers repeated more details than liars across all question format conditions, but the non-sequentially ordered questions revealed the highest effect size $(d=1.48)$ compared to the sequentially ordered questions and to the free recall. This is in line with 
previous research on lie detection which demonstrated that liars become less consistent than truth-tellers when a change in question format is introduced in the interview (e.g. Leins et al., 2012; Shaw et al., 2014).

The discriminant analysis corroborated these findings. Non-sequentially ordered questions showed the highest correct classification rate (78\%) compared to the other two question formats. Hence, asking non-sequentially ordered questions in a second interview is a better strategy in reducing liars' consistency and in accurately classifying liars from truth-tellers than asking sequentially ordered questions or requesting a free recall.

Interestingly, liars (who were asked to lie about the critical event but to tell the truth about the non-critical event) repeated fewer details than truth-tellers for the non-critical event. This is in contrast with our prediction that liars would perform the same as truth-tellers when they truthfully report about the non-critical event. It might be that liars were cognitively loaded because they had to recall two events and -unlike truth-tellers- lie about one of the events. It is possible that liars' cognitive resources are depleted when they have to lie about one of the events, and as a result, it becomes difficult for them to maintain consistency. However, the liars' reported strategies provides another explanation for this finding. Approximately $45 \%$ of liars indicated that they tried to maintain consistency across interviews about both events. They actually achieved this as the within-subjects analyses indicated. Many liars reported that they thought it will be difficult to remain consistent when deceptively answering questions about the critical event. Therefore, they adopted the strategy of providing fewer repetitions for the noncritical event to lower their 'baseline consistency'. Applying this strategy, the number of repetitions they provided when they lied (regarding the critical event) would match the number of repetitions they provided when they told the truth. Nonetheless, these repeated details were 
fewer than those provided by truth-tellers. These two explanations do not necessarily contradict each other, because the increased cognitive load and the deliberate strategy may be occurring simultaneously. Even though liars attempted to maintain consistency across events, they may as well have found it difficult to lie about one of the two events, which further decreased their consistency levels.

\section{Limitations and Future Directions}

We could not analyze reminiscences and contradictions in our study because they did not occur frequently enough to be analyzed. Previous studies on lie detection have also reported that contradictions could not be analyzed for the same reason (e.g., Ewens et al., 2015; Granhag \& Strömwall, 2002). The very few reminiscences in our study might be explained by the difficulty of the task for participants, because they had to report about two events. The literature on reminiscences corroborates these findings, because cognitive interference inhibits individuals from providing additional information (Erdelyi, 1996; Ewens et al., 2015). Even though specific questions are more likely to increase reminiscences than a free recall (Fisher et al., 2009), it appears that increasing the difficulty of the questions by asking about two events rather than one event may interrupt memory retrieval and impede reminiscences. As previous research on reminiscences in the eyewitness and lie detection literatures demonstrated, reminiscences are characteristic of truth-tellers' statements rather than of liars' statement, so researchers in both fields may further examine reminiscences amongst innocent suspects when more than one event is reported.

It is worth noting that we deliberately did not counterbalance the order of the discussed events. We introduced the critical event after the non-critical event, because liars find it more 
difficult to start responding truthfully and then to lie rather than vice versa (Vrij, Leal, Mann, \& Fisher, 2012). We also presented the non-sequentially ordered questions in the same order with questions about the non-critical event followed by the same questions about the critical event. Hence, liars might have been able to predict the nature of subsequent questions as the interview progressed. Non-sequentially ordered questioning may become more effective if the nature and order of the questions are varied within an interview. For example, the interviewer may ask questions about what each person said during each event as well as about the events' details, including temporal and spatial details (which are details that suspects do not anticipate they will be asked; Vrij et al., 2009).

Participants viewed a Skype discussion and were asked to recall it and/or distort some of the details. This may not reflect real criminal cases because informants are often more involved in overheard discussions, so this might have affected the ecological validity of our study. Even though we aimed to examine overheard discussions by informants, it is important for future studies to investigate how liars' and truth-tellers' statement consistency changes as a function of question format when they engage in the discussions themselves. In addition, sometimes informants engage in actions rather than discussions, so future studies might investigate consistency in reporting actions rather than discussions.

Our findings suggest that liars adopt different strategies when they have to report about more than one event compared to only one event as it becomes more difficult for them to use a rehearse and repeat strategy (Granhag \& Strömwall, 1999). Liars often incorporate lies and truths in a single account to make it easier to fabricate the lie (Leins, Fisher, \& Ross, 2013), so their deliberation and cognitive load may increase when they have to report about two events, even 
when one of the events is truthful. We found that non-sequentially ordered questions magnified the differences between liars and truth-tellers for two events, but we expect this questioning to be more effective when used for more than two events. However, more research is needed to further explore liars' performance when they report about more than one event and when they tell the truth and lie in a single account.

Lastly, the finding that liars were significantly less consistent than truth-tellers even when telling the truth was interesting. Liars seem to use the same strategy when they tell the truth and when they lie in a single interview. It may be that in investigative settings, suspects who provide few repetitions for all reported events may be lying about at least one of the events. Of course, in our experimental design the investigator knew the facts about the first discussed event, the noncritical event. This may not always be the case in real life. However, in real life investigators may often be able to verify some of the information of one of the events discussed in a first interview and may reach the conclusion that the suspect was truthful when describing that event. As our findings show, suspects who provide only few repetitions and omit a large amount of information about this verified information in a subsequent interview may be suspected of lying about the other nonverifiable information. When asking non-sequentially ordered questions decreases repetitions, suspicion may be well justified as our discriminant analysis showed that this technique may help investigators accurately classify liars $78 \%$ of the time. Moreover, the large effect sizes we found when using non-sequentially ordered questions indicates that investigators can detect decreased consistency while they are conducting the interview.

Non-sequentially ordered questions affect truth-tellers as much as liars. These questions disrupt the natural and chronological recall by truth-tellers and decrease their reporting accuracy, so they may not match proposed guidelines on good interviewing practice (Fisher et al., 2009; 
Walsh, Oxburgh, Redlich, \& Myklebust, 2015). However, our findings that truth-tellers were significantly more consistent than truth-tellers demonstrate that truth-tellers did not find responding to these questions as difficult as liars found them and they managed to repeat a good amount of information. Hence, these questions may be used in investigative contexts where investigators have sufficient bases to assume that the suspect may be deceptive or in contexts where possible deception is detrimental for the case.

The current research is the first to investigate non-sequentially ordered questions when liars report about two events. The large effect size for repetitions when this non-sequentially ordered questions were used compared to a free recall or to sequentially ordered questions suggests that it is a promising interview technique for use with potentially unreliable informants. More research is needed on this technique to demonstrate its applied potential.

\section{Conflict of Interest Statement}

The authors declare that there are no conflicts of interest. 


\section{References}

Cohen, J. (1992). A power primer. Psychological Bulletin, 112, 155-159. doi: 10.1037/00332909.112.1.155

du Prel, J. B., Hommel, G., Röhrig, B., \& Blettner, M. (2009). Confidence interval or p-value?: Part 4 of a series on evaluation of scientific publications. Deutsches Ärzteblatt International. 106, 335-339. doi: 10.3238/arztebl.2009.0335

Erdelyi, M. H. (1996). The recovery of unconscious memories: Hypermnesia and reminiscence. Chicago: The University of Chicago Press.

Evans, J. R., \& Fisher, R. P. (2011). Eyewitness memory: Balancing the accuracy, precision and quantity of information through metacognitive monitoring and control. Applied Cognitive Psychology, 25, 501-508. doi: 10.1002/acp.1722

Ewens, S., Vrij, A., Mann, S., \& Leal, S. (2015). Using the reverse order technique with nonnative speakers or through an interpreter. Applied Cognitive Psychology. Advance online publication. doi: 10.1002/acp.3196

Fisher, R. P., Brewer, N., \& Mitchell, G. (2009). The relation between consistency and accuracy of eyewitness testimony: Legal versus cognitive explanations. In R. Bull, T. Valentine, \& T. Williamson (Eds.), Handbook of psychology of investigative interviewing: Current developments and future directions (pp. 121-136). Chichester: John Wiley \& Sons.

Fisher, R. P., Vrij, A., \& Leins, D. A. (2013). Does testimonial inconsistency indicate memory inaccuracy and deception? Beliefs, empirical research, and theory. In B. S. Cooper, D. Griesel, \& M. Ternes (Eds.), Applied issues in investigative interviewing, eyewitness memory, and credibility assessment (pp. 173-189). New York: Springer. 
Fritz, C. O., Morris, P. E., \& Richler, J. J. (2012). Effect size estimates: current use, calculations, and interpretation. Journal of Experimental Psychology: General, 141, 2-18. doi: $10.1037 / \mathrm{a} 0024338$

Granhag, P. A., \& Strömwall, L. A. (1999). Repeated interrogations-Stretching the deception detection paradigm. Expert Evidence, 7, 163-174. doi: 10.1023/A:1008993326434

Granhag, P. A., \& Strömwall, L. A. (2002). Repeated interrogations: Verbal and non-verbal cues to deception. Applied Cognitive Psychology, 16, 243-257. doi: 10.1002/acp.784

Granhag, P. A., Strömwall, L. A., \& Jonsson, A. C. (2003). Partners in crime: How liars in collusion betray themselves. Journal of Applied Social Psychology, 33, 848-868. doi: 10.1111/j.1559-1816.2003.tb01928.x

Greer, S. (1995). Towards a sociological model of the police informant. The British Journal of Sociology, 46, 509-527. doi: 10.2307/591854

Harfield, C. (2012). Police informers and professional ethics. Criminal Justice Ethics, 31, 73-95. doi: 10.1080/0731129X.2012.696960

Hartwig, M., Granhag, P. A., Strömwall, L. A., Wolf, A. G., Vrij, A., \& Roos af Hjelmsäter, E. (2011). Detecting deception in suspects: Verbal cues as a function of interview strategy. Psychology, Crime \& Law, 17, 643-656. doi: 10.1080/10683160903446982

Innes, M. (2000). 'Professionalizing' the role of the police informant: The British experience. Policing and Society: An International Journal of Research and Policy, 9, 357-383. doi: $10.1080 / 10439463.2000 .9964823$ 
Leins, D. A., Fisher, R. P., \& Ross, S. J. (2013). Exploring liars' strategies for creating deceptive reports. Legal and Criminological Psychology, 18, 141-151. doi: 10.1111/j.20448333.2011.02041.x

Leins, D. A., Fisher, R. P., \& Vrij, A. (2012). Drawing on liars' lack of cognitive flexibility: Detecting deception through varying report modes. Applied Cognitive Psychology, 26, 601607. doi: $10.1002 /$ acp. 2837

Maguire, M., \& John, T. (1995). Intelligence, surveillance and informants: Integrated approaches (Police Research Group Paper No. 64). London: Home Office.

McGarrell, E. F., Freilich, J. D., \& Chermak, S. (2007). Intelligence-led policing as a framework for responding to terrorism. Journal of Contemporary Criminal Justice, 23, 142-158. doi: $10.1177 / 1043986207301363$

Miller, J. M. (2011). Becoming an informant. Justice Quarterly, 28, 203-220. doi: $10.1080 / 07418825.2010 .506881$

Rosenfeld, R., Jacobs, B. A., \& Wright, R. (2003). Snitching and the code of the street. The British Journal of Criminology, 43, 291-309. doi: 10.1093/bjc/43.2.291

Shaw, D., Vrij, A., Leal, S., \& Mann, S. (2014). 'We'll take it from here': The effect of changing interviewers in information gathering interviews. Applied Cognitive Psychology, 6, 908-916. doi: $10.1002 /$ acp.3072

Stabile, E. (2014). Recruiting terrorism informants: The problems with immigration incentives and the S-6 visa. California Law Review, 102, 235-276. doi: 10.2139/ssrn.2228859 
Strömwall, L. A., \& Granhag, P. A. (2003). How to detect deception? Arresting the beliefs of police officers, prosecutors and judges. Psychology, Crime \& Law, 9, 19-36. doi: $10.1080 / 10683160308138$

Vredeveldt, A., van Koppen, P. J., \& Granhag, P. A. (2014). The inconsistent suspect: A systematic review of different types of consistency in truth tellers and liars. In R. Bull (Ed.), Investigative interviewing (pp. 183-207). New York: Springer.

Vrij, A. (Ed.). (2008). Detecting lies and deceit: Pitfalls and opportunities. Chichester: John Wiley \& Sons.

Vrij, A., Granhag, P. A., \& Porter, S. (2010). Pitfalls and opportunities in nonverbal and verbal lie detection. Psychological Science in the Public Interest, 11, 89-121. doi: $10.1177 / 1529100610390861$

Vrij, A., Leal, S., Granhag, P. A., Mann, S., Fisher, R. P., Hillman, J., \& Sperry, K. (2009). Outsmarting the liars: The benefit of asking unanticipated questions. Law and Human Behavior, 33, 159-166. doi: 10.1007/s 10979-008-9143-y

Vrij, A., Leal. S., Mann, S., \& Fisher, R. (2012). Imposing cognitive load to elicit cues to deceit: Inducing the reverse order technique naturally. Psychology, Crime, \& Law, 18, 579-594. doi: 10.1080/1068316X.2010.515987

Walsh, D., Oxburgh, G. E., Redlich, A. D., \& Myklebust, T. (2015). International developments and practices in investigative interviewing and interrogation (Volume 1: Victims and witnesses). Oxford: Routledge Press. 
Table 1

Means and Standard Deviations of the Dependent Variables for the Non-critical and Critical Events

\begin{tabular}{lcccc}
\hline & \multicolumn{2}{c}{ Truth } & \multicolumn{2}{c}{ Lie } \\
\cline { 2 - 5 } & $M$ & $S D$ & $M$ & $S D$ \\
\hline Non-critical event & & & & \\
Repetitions & 26.92 & 9.95 & 20.84 & 9.61 \\
Omissions & 6.40 & 4.03 & 6.64 & 3.95 \\
Reminiscences & 4.87 & 2.17 & 2.67 & 1.28 \\
Contradictions & 0.20 & 0.46 & 0.21 & 0.44 \\
& & & & \\
Critical event & & & & \\
Repetitions & 32.13 & 10.66 & 22.8 & 9.85 \\
Omissions & 10.91 & 6.43 & 13.84 & 7.35 \\
Reminiscences & 3.38 & 1.25 & 4.24 & 2.15 \\
Contradictions & 0.32 & 0.61 & 0.48 & 0.76 \\
\hline
\end{tabular}


Table 2

Repetitions for the Non-critical and Critical Events as a Function of Veracity and Second Interview Question Format

\begin{tabular}{lccccccc}
\hline & \multicolumn{2}{c}{ Truth } & \multicolumn{2}{c}{ Lie } & & \\
\cline { 2 - 8 } & $M$ & $S D$ & $M$ & $S D$ & $F$ & $p$ & $d[95 \% \mathrm{CI}]$ \\
\hline $\begin{array}{l}\text { Non-critical event } \\
\text { Repetitions }\end{array}$ & & & & & & & \\
$\quad$ Free recall & 30.88 & 10.80 & 24.12 & 12.25 & 4.28 & .044 & $0.59[0.02,1.15]$ \\
$\quad$ Sequential & 25.64 & 9.66 & 20.20 & 8.17 & 4.63 & .037 & $0.61[0.04,1.18]$ \\
$\quad$ Non-sequential & 24.24 & 8.36 & 18.20 & 6.99 & 7.68 & .008 & $0.78[0.21,1.36]$ \\
Total & 26.92 & 9.95 & 20.84 & 9.61 & 15.25 & $<.001$ & $0.62[0.29,0.95]$ \\
& & & & & & & \\
Critical event & & & & & & & \\
Repetitions & & & & & & & \\
$\quad$ Free recall & 35.40 & 12.79 & 26.88 & 12.31 & 5.76 & .02 & $0.68[0.11,1.25]$ \\
$\quad$ Sequential & 30.12 & 9.32 & 22.96 & 7.52 & 8.94 & .004 & $0.85[0.27,1.42]$ \\
$\quad$ Non-sequential & 30.88 & 9.12 & 18.56 & 7.42 & 27.46 & $<.001$ & $1.48[0.86,2.11]$ \\
$\quad$ Total & 32.13 & 10.66 & 22.80 & 9.85 & 32.85 & $<.001$ & $0.91[0.57,1.25]$ \\
\hline
\end{tabular}


Table 3

Frequency and Percentage of Occurrence of Strategies used by Truth-tellers and Liars to Convince the Interviewer of their Responses

\begin{tabular}{lcc}
\hline Category & Frequency & Percentage \\
\hline Truth-tellers & 38 & $51 \%$ \\
Providing details & 24 & $32 \%$ \\
Being honest & 12 & $16 \%$ \\
Reporting in chronological order & 9 & $12 \%$ \\
Using memory enhancement strategies & 6 & $8 \%$ \\
Maintaining consistency & & \\
Liars & 34 & $45 \%$ \\
Maintaining consistency & 24 & $32 \%$ \\
Staying close to the truth & 13 & $17 \%$ \\
Providing as much details as possible & 8 & $11 \%$ \\
Keeping the story simple & 4 & $5 \%$ \\
Rehearsing the lie & 6 & $8 \%$ \\
Other & & \\
\hline
\end{tabular}

Note. The percentages are calculated for truth-tellers and liars separately. The total exceeds $100 \%$ for each group because each participant could contribute to more than one category. 
Figure 1. Comparisons of the number of repetitions provided by truth-tellers and liars in each of the Question Format Conditions for the Non-Critical Event

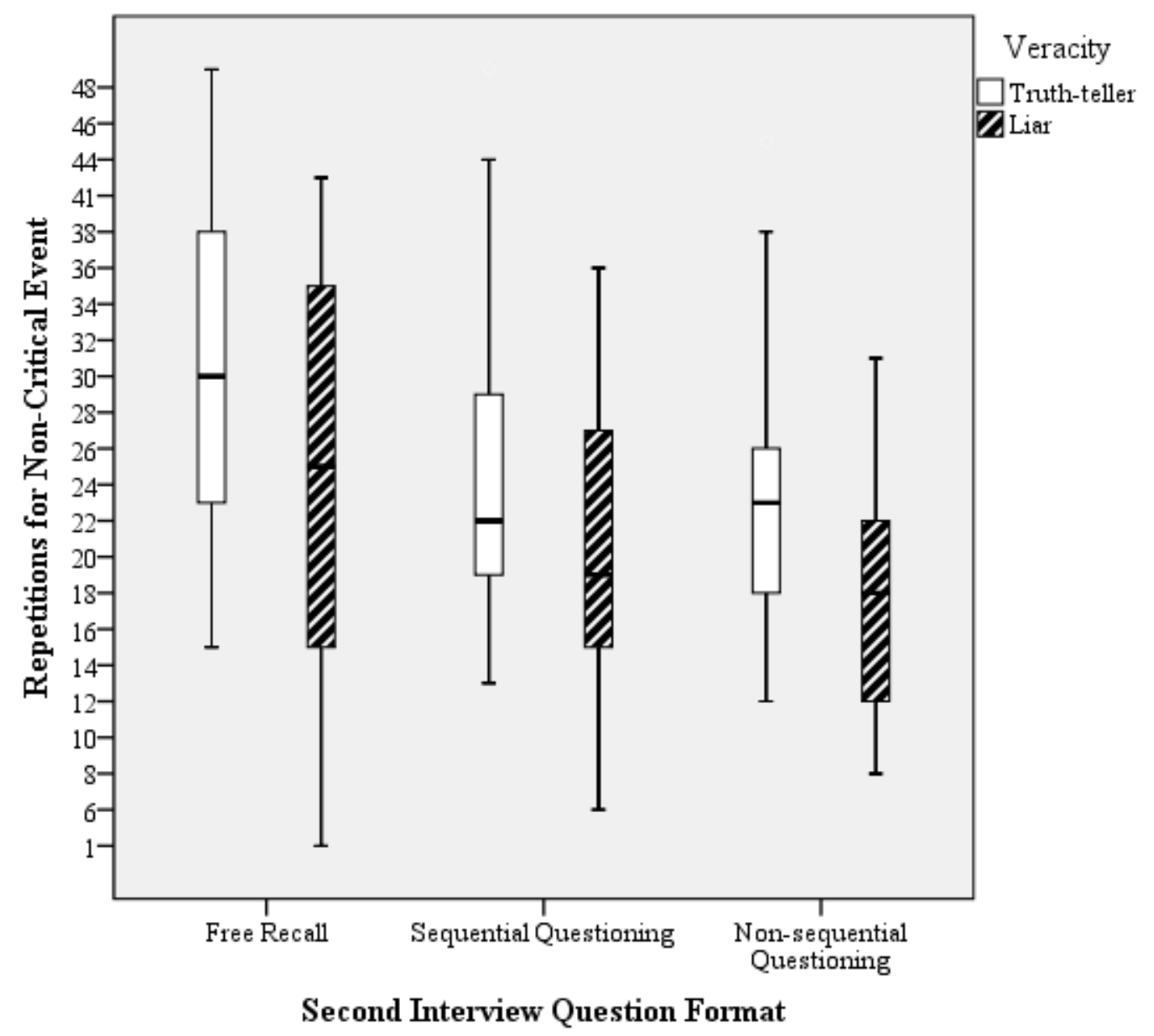


Figure 2. Comparisons of the number of repetitions provided by truth-tellers and liars in each of the Question Format Conditions for the Critical Event

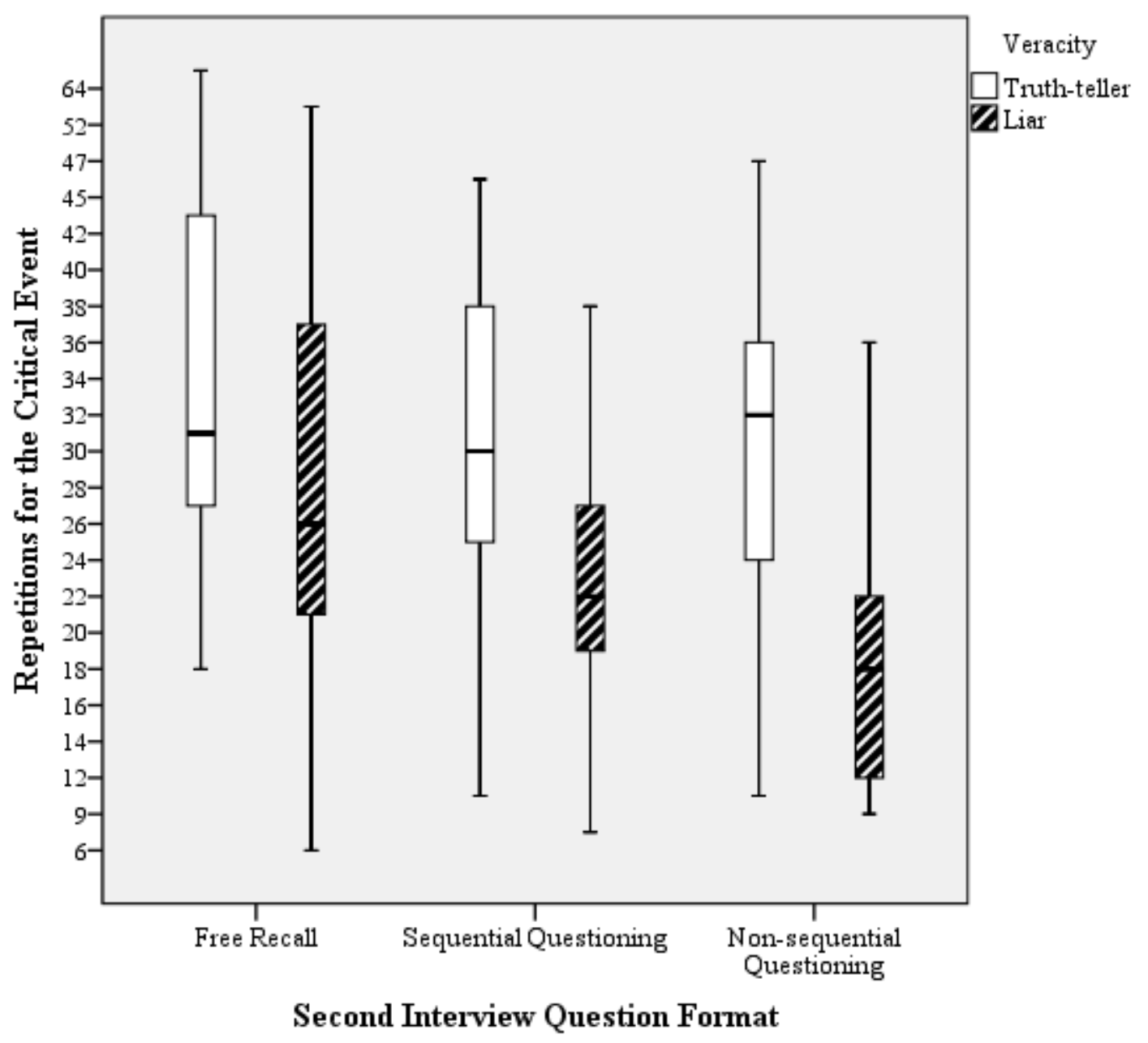




\section{Appendix}

\section{Sequentially Ordered Questions}

1.Tell me in detail what Chief said when they were discussing the trip to Prague?

2. Tell me in detail what Tiger said when they were discussing the trip to Prague?

3. Tell me in detail what Bird said when they were discussing the trip to Prague?

4. Tell me in detail what Chief said when they were discussing the spying mission against the terrorist?

5. Tell me in detail what Tiger said when they were discussing the spying mission against the terrorist?

6. Tell me in detail what Bird said when they were discussing the spying mission against the terrorist?

\section{Non-sequentially Ordered Questions}

1. Tell me in detail what Chief said when they were discussing the trip to Prague?

2. Tell me in detail what Chief said when they were discussing the spying mission against the terrorist?

3. Tell me in detail what Tiger said when they were discussing the trip to Prague?

4. Tell me in detail what Tiger said when they were discussing the spying mission against the terrorist?

5. Tell me in detail what Bird said when they were discussing the trip to Prague?

6. Tell me in detail what Bird said when they were discussing the spying mission against the terrorist?" 